\title{
Aspects of Atlas Mapping for Analysis of Energy Infrastructure in Different Regions
}

\author{
I.L. Trofimov*, L.N. Trofimov
}

Melentiev Energy Systems Institute of Siberian Branch of Russian Academy of Sciences, Irkutsk, Russiaa

\begin{abstract}
The paper addresses the visualization and systematization of cartographic material for analyzing energy infrastructure in various world regions. It discusses the technology (architecture) for building maps based on the concept of atlas mapping. An interface was developed for the construction of interactive maps and navigation in any section of the world atlas - from the level of world continents to a detailed map of any region within the country. We have constructed and stored contour maps of all countries of the world in the database of the computing geoinformation system (CGIS). CGIS allows constructing hybrid maps, which contain vector and raster map layers with the energy infrastructure overlaid on them in the selected territory. An algorithm was constructed to search for energy objects and administrative entities in any country or region of the world. The atlases built by CGIS are used at Melentiev Energy Systems Institute (MESI) of the Siberian Branch of the Russian Academy of Sciences to plot the solutions obtained with the optimization model ORIRES (which reflects the optimal operation of the interconnected power systems in different scenarios) on a map of a selected area or region.
\end{abstract}

Index Terms: Atlas mapping, geo-information system, computing system, data processing, hybrid map, tiles, map layer.

\footnotetext{
* Corresponding author.

E-mail: t john88@isem.irk.ru
}

http://dx.doi.org/10.38028/esr.2021.01.0006

Received March 29, 2021. Revised April 13, 2021.

Accepted April 22, 2021. Available online May 26, 2021.

This is an open access article under a Creative Commons Attribution-NonCommercial 4.0 International License.

C) 2021 ESI SB RAS and authors. All rights reserved.

\section{INTRODUCTION}

International experience in establishing Interstate Power Grids (ISPG) shows that electric power integration is cost-effective for the parties involved. The pre-design stage of the ISPG development requires its technical and economic analysis, justification, and comprehensive analysis of the energy infrastructure in the region. This is especially relevant because the project of Northeast Asia ISPG has begun to actively develop in recent years owing to the efforts made by the United Nations ESCAP (Energy and Social Commission of Asia Pacific region) and the GEIDCO (Global Energy Integration Organization) from China. A research team from MESI is also involved in this research. The study on the prospective ISPG expansion relies on the optimization model ORIRES.

The ORIRES model is used to identify the optimal installed capacities by generation type (thermal, hydro, wind, and solar), optimal transfer capabilities, and operating conditions of electric ties for each power system in the ISPG scheme for the target year. The optimal solution of the model is determined by the minimum value of the objective function (annualized costs) for the entire power system or interconnection. These costs consist of fuel, investment, operating, and maintenance costs for power plants; and investment, operating, and maintenance costs for transmission lines. Transmission losses are also factored in. Environmental policy tools, like $\mathrm{CO}_{2}$ emission taxes, can also be incorporated into the objective function if needed. The model was developed by Lev Belyaev, Vladimir Savel'ev, Oleg Khamisov, Sergei Podkovalnikov and Lyudmila Chudinova. The ORIRES model is described in detail in the monograph "The effectiveness of interstate electric power interconnections," 2008 (in Russian) [1, 2].

The model is an essential part of the developed geoinformation computing system (CGIS). CGIS allows us to enter, configure, and change all the model parameters; run the lp optimizer (for optimal solution finding); create and 


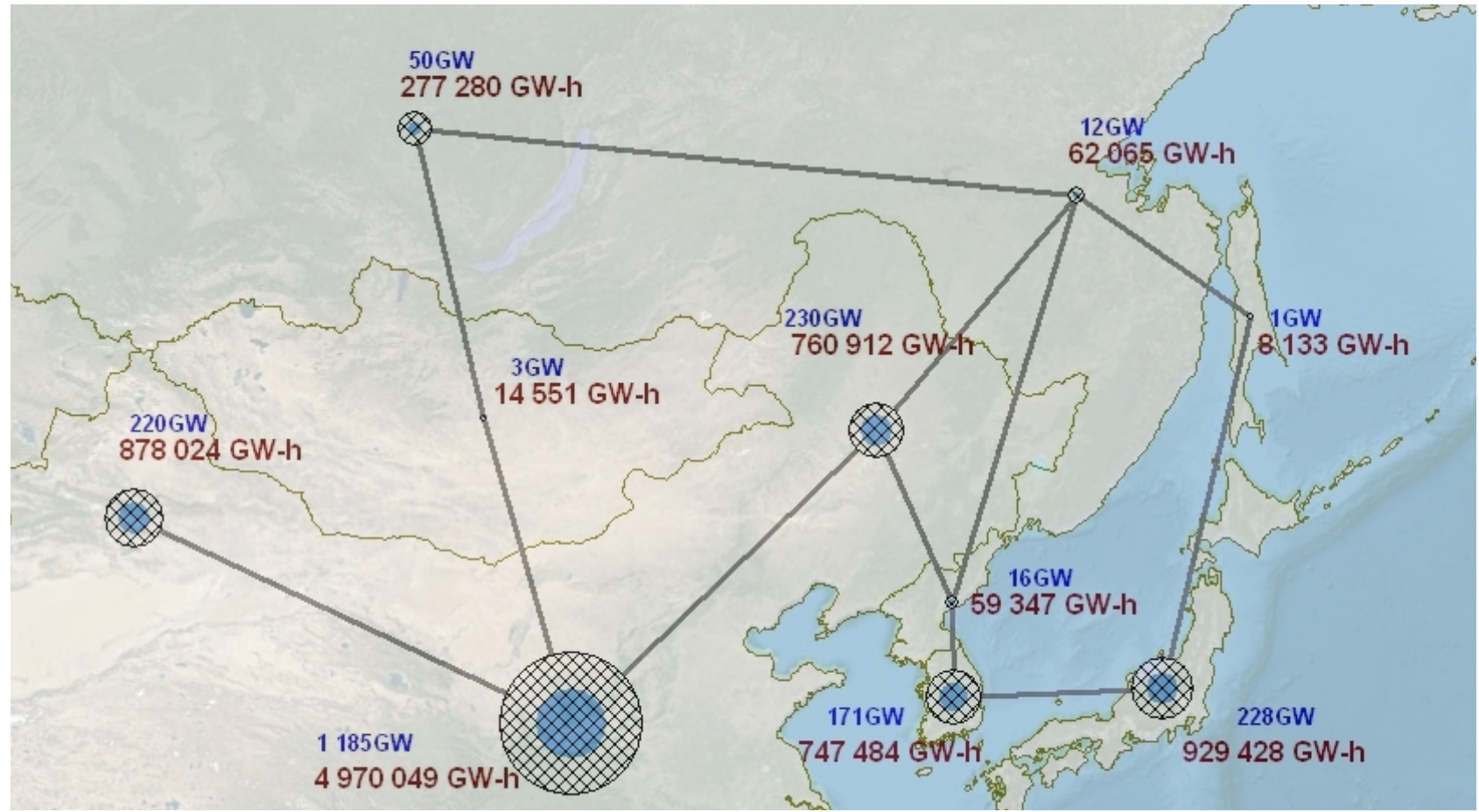

Fig. 1. Representation of a 10-node (aggregated energy power system) Northeast Asia interstate power grid.

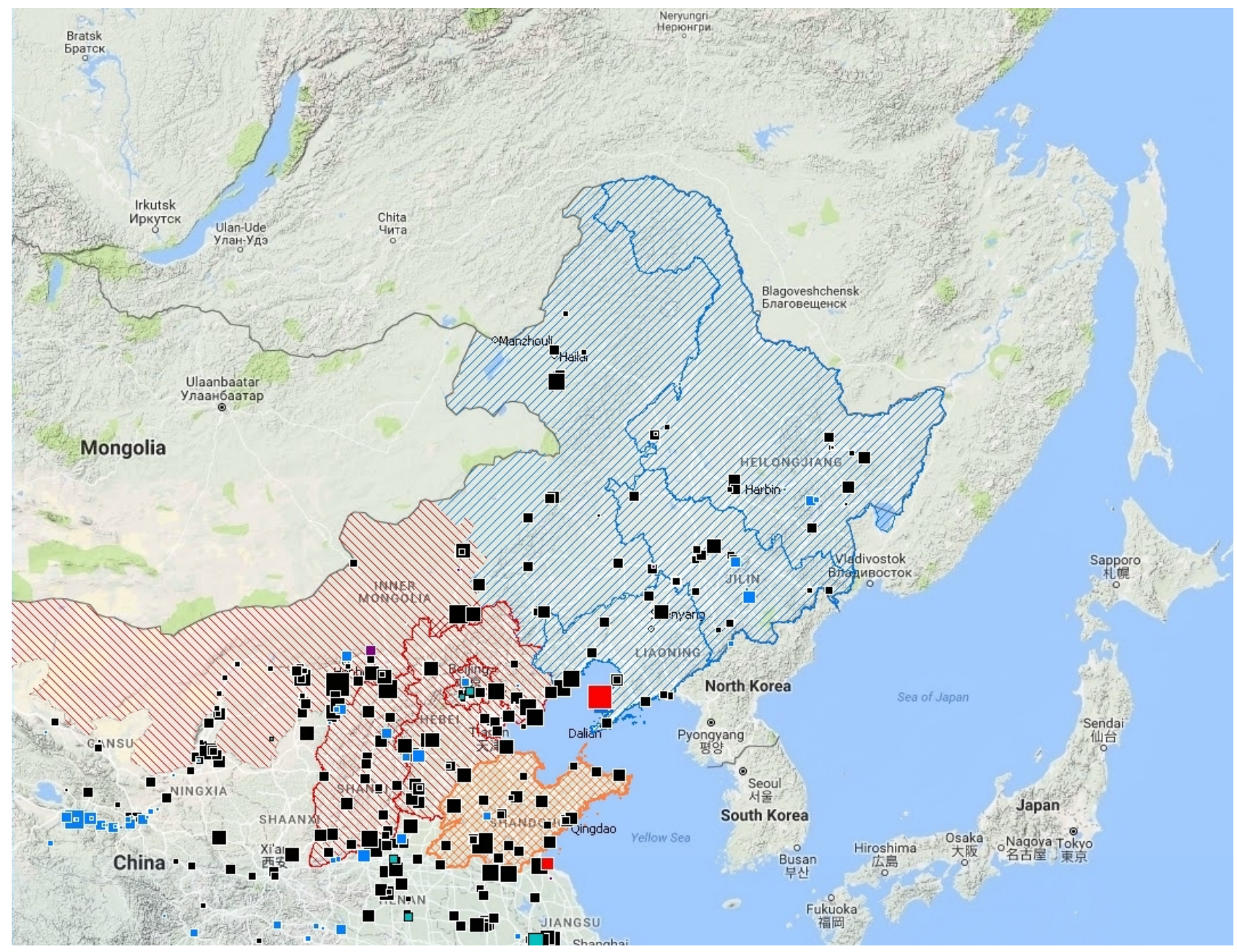

Fig. 2. Northeast China power plants geo-location from the database. 


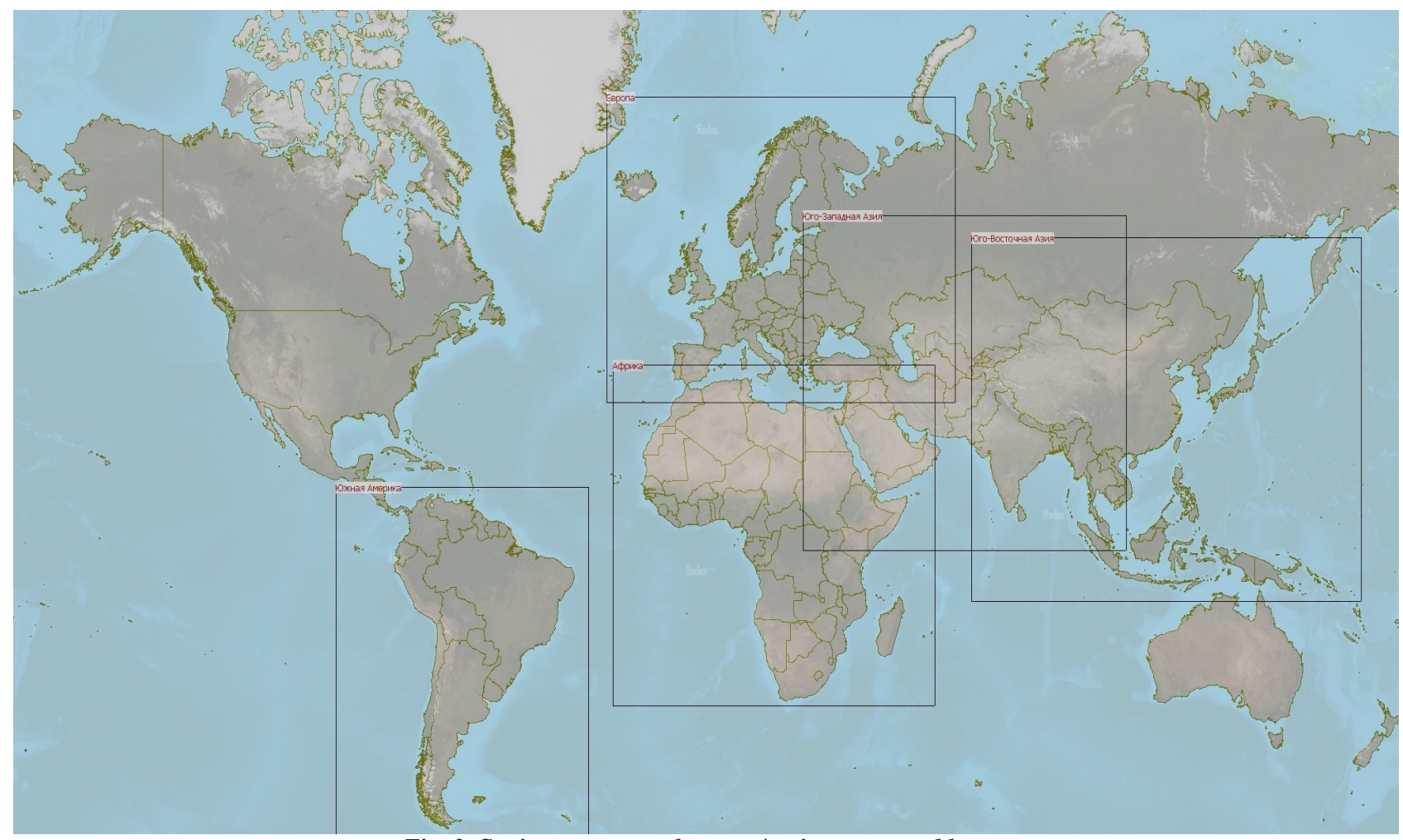

Fig. 3. Setting a rectangular area/region on a world map.

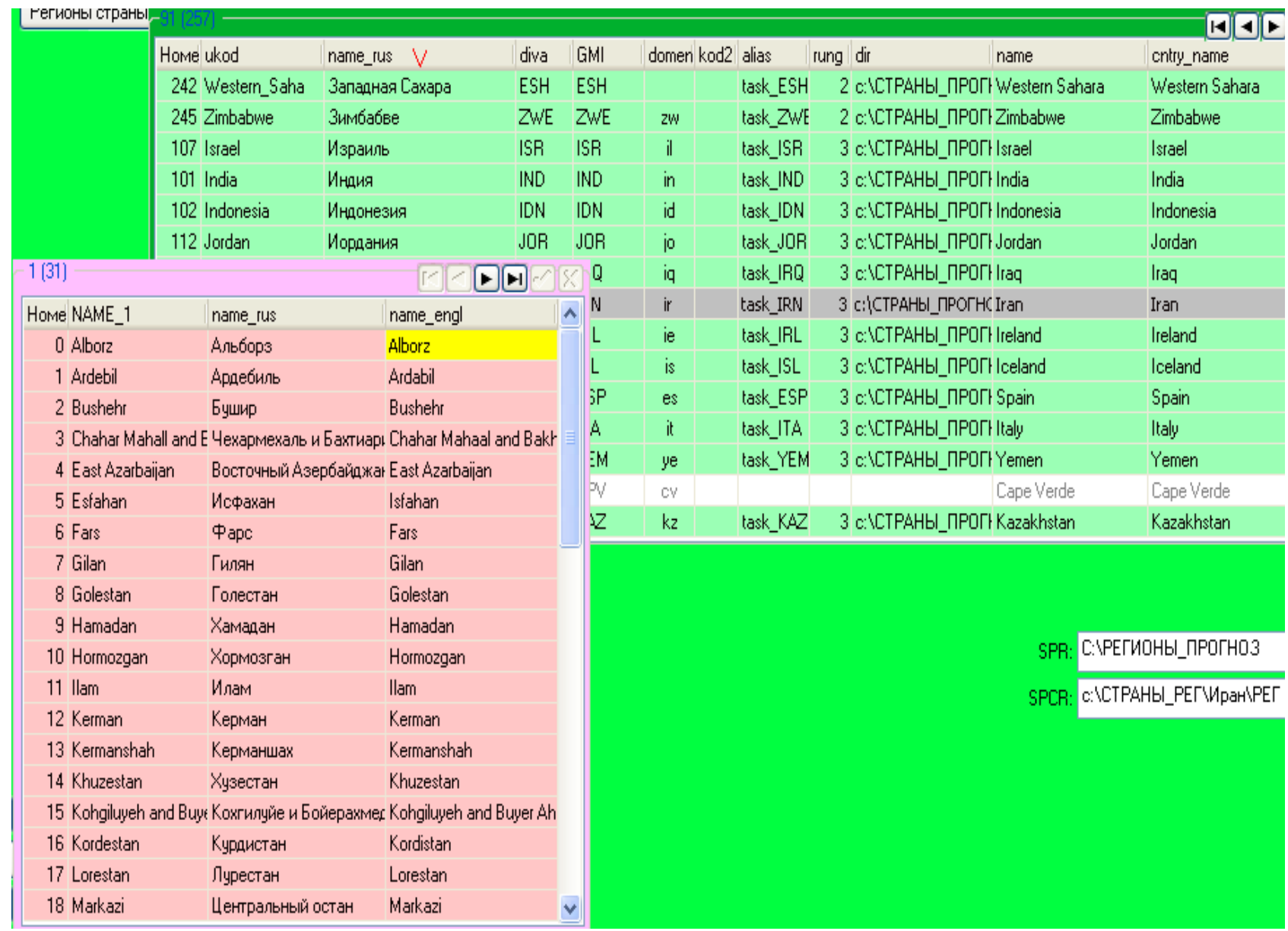

Fig. 4. List of the world's countries with provinces in the CGIS interface. 
store results in the original energy database and display the obtained results in tabular, graphic, and cartographic forms [3-6].

This paper discusses a study on the visualization of processed data in a cartographic interface.

\section{SOFTWARE OVERVIEW}

Many researchers in many countries investigate interstate power grid expansion. Different kinds of software were developed for power grids modeling. Nevertheless, most of them can only solve the problem of electricity redistribution and do not use any optimization models [7-11].

There is a need for more comprehensive research on ISPG expansion. Therefore, our study relies on an optimization model. We collect and process large arrays of data for the optimization model, which requires visual analysis of the obtained results.

Most GIS systems have no computing part and do not work with optimization models. We have developed both the data processing and computing geo-information system in one software product.

Multipurpose geo-information systems like ArcGIS or MapInfo solve a great number of problems associated with geospatial data processing [12, 13]. They have some similar functions:

- support of raster and vector data,

- use geocoding algorithms,

- work with geo-databases,

- support various geo-projections.

These systems, however, have disadvantages:

- high price (from 5000 \$ per 1 license of ArcGIS),

- complex control elements,

- are not intended for energy data processing and representation.

Multipurpose software does not solve our research problems. We needed problem-oriented software with a convenient user interface to work with the optimization model and analyze the obtained results.

CGIS integrates both computing and informational components in one software product. CGIS consists of several functional parts (software modules): a graphic module for visual analysis of processed data, a geoinformation and cartographic module, and a module for working with the ORIRES model.

The main features of CGIS for working with the ORIRES model are:

- Making changes to the mathematical equations written in linear programming (lp optimizer) language;

- Enabling/disabling model constraints;

- Operational tuning/editing of input parameters for the model;

- Including/deleting model nodes (and corresponding ties) in the diagram of electric power systems and interconnections;
- Creating the inherited scenarios (scenario tree), their storage in the database, and comparison;

- Controlling and analyzing input parameters of the model (meeting given constraints).

All data used in the CGIS are stored and processed in their energy/power database.

We propose an original CGIS for the representation and analysis of energy infrastructure in various regions of the world with an integrated computing part. The data overlaid on the map can be those on energy facilities (power plants) and electric power systems, as well as the data from calculations with the built-in optimization model. This feature distinguishes the proposed software from others.

Another feature of the developed software is that it allows visualization of the model results and the energy infrastructure of any region of the world (data on all energy/power facilities collected in the database) on a map. This provides the most complete information on the energy infrastructure in any region to conduct further research.

The processing and analysis of a large amount of complex and rapidly growing data require dedicated technologies for data management and storage. CGIS works with its object-oriented energy database developed by the authors. The database objects contain geographical information for visual representation and qualitative analysis, information on the relationships between objects and their regional affiliation, technical and economic parameters, and other information.

These data are downloaded to the database from various sources: world energy outlook, world power plant database, enipedia.org, and others. All data are stored in a special object format. Details on the object format of the database can be found in the paper "The Computing and Information System for Study of Scenarios for Interstate Power Grid Expansion" [6].

To analyze the results of solving the model in the cartographic module, the user can build a scheme of ISPG with set parameters and connections between the nodes (interstate electric ties) on the map. Fig. 1 shows the hybrid map with a 10-node scheme of the Northeast Asia interstate power grid for the 2040 target year.

In addition, the user can construct a map with energy/ power plants in any part of the studied region, Fig. 2.

\section{A CONCEPT OF ATLAS MAPPING}

A dedicated interface was developed for the construction of interactive maps and navigation in any section of the world atlas, from the level of world continents to a detailed map of any region within the country, Fig. 3.

Over the year 2019, we constructed and stored contour maps of all countries of the world with administrative divisions (country regions), with their names in Russian and English, in the CGIS database. This interface allows building maps of any territory, including several countries or regions, on a given scale. One of our energy database 


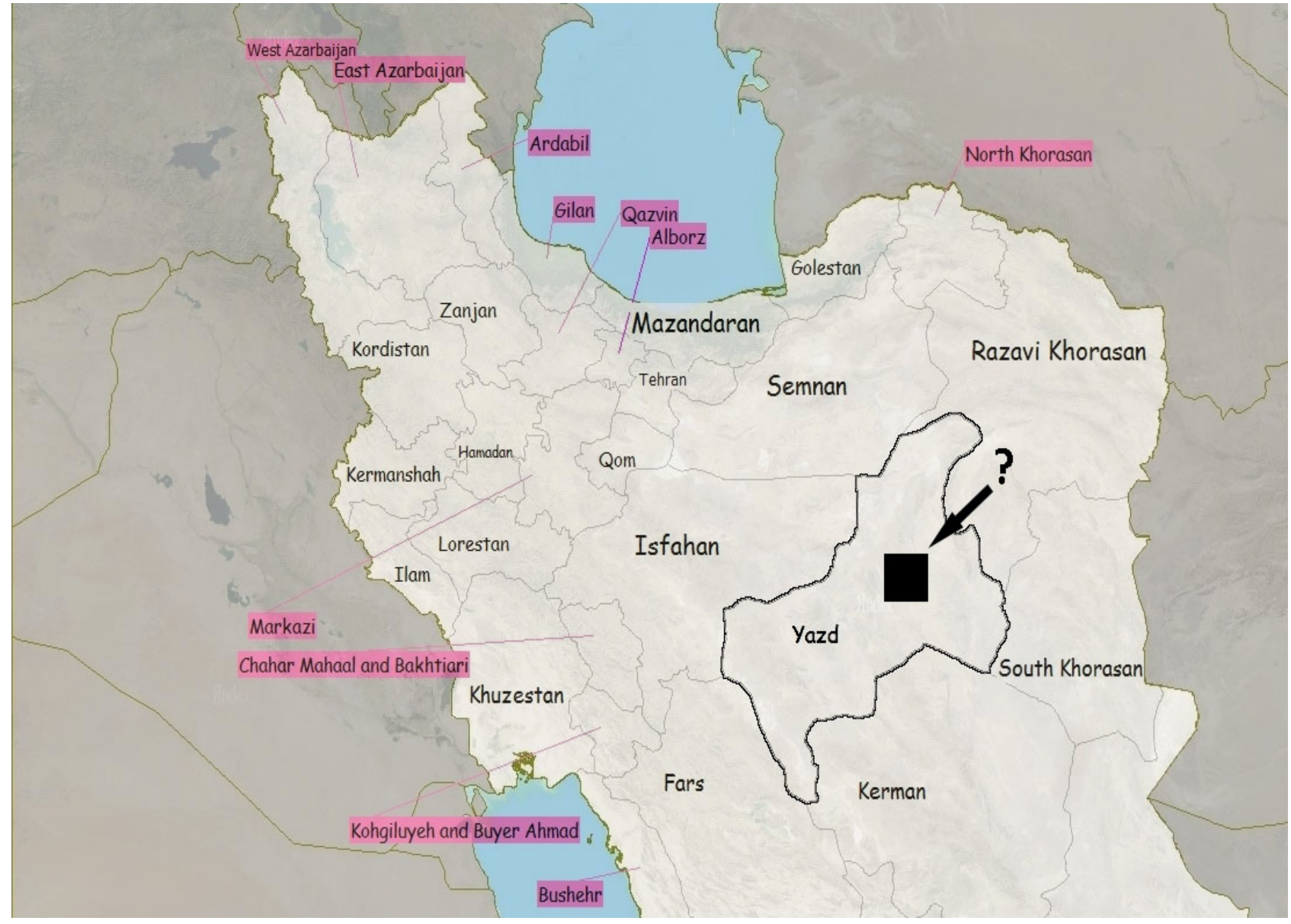

Fig. 5. Search for an object belonging to a specific closed polygon.
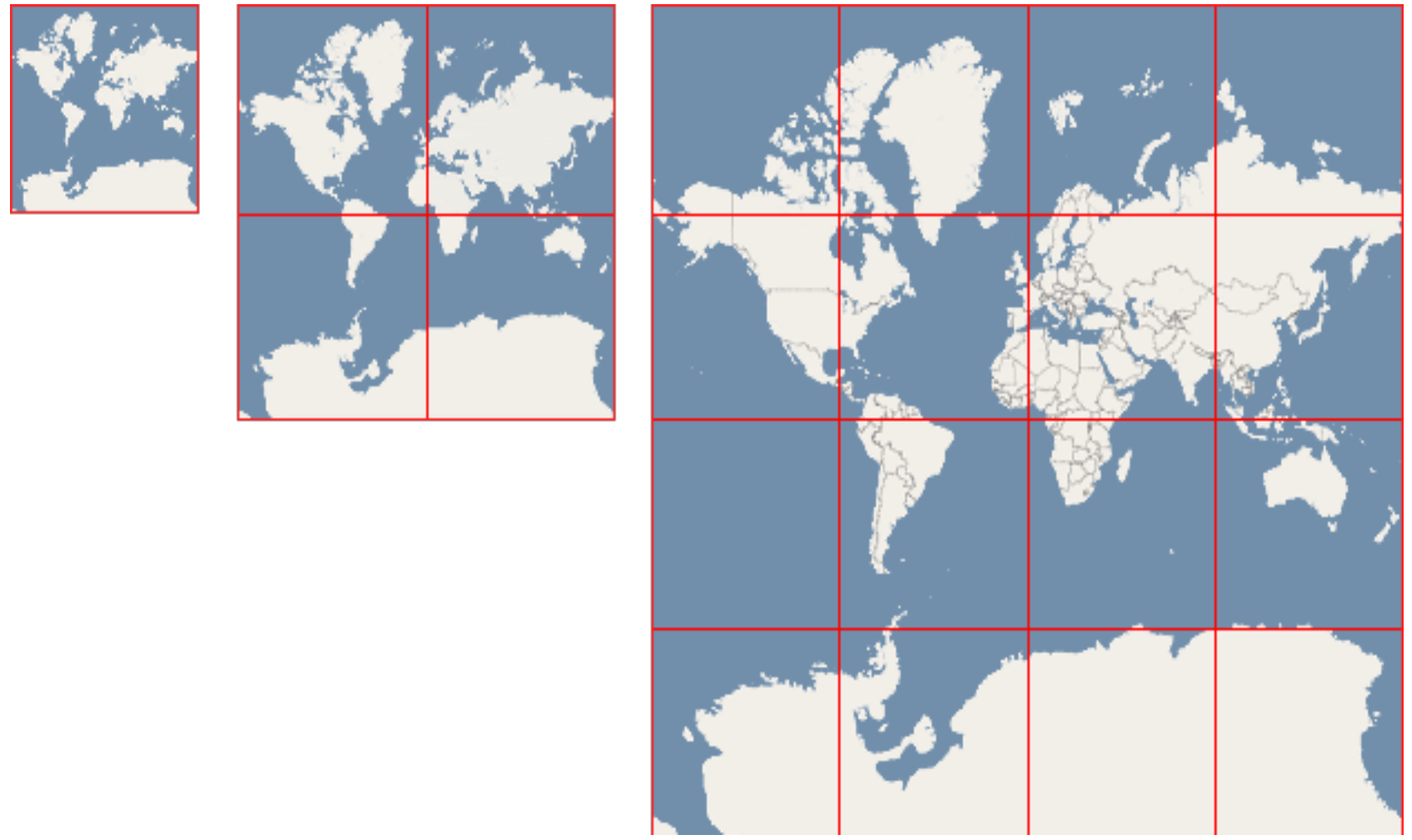

Fig. 6. Google and Yandex map tile zooming. 


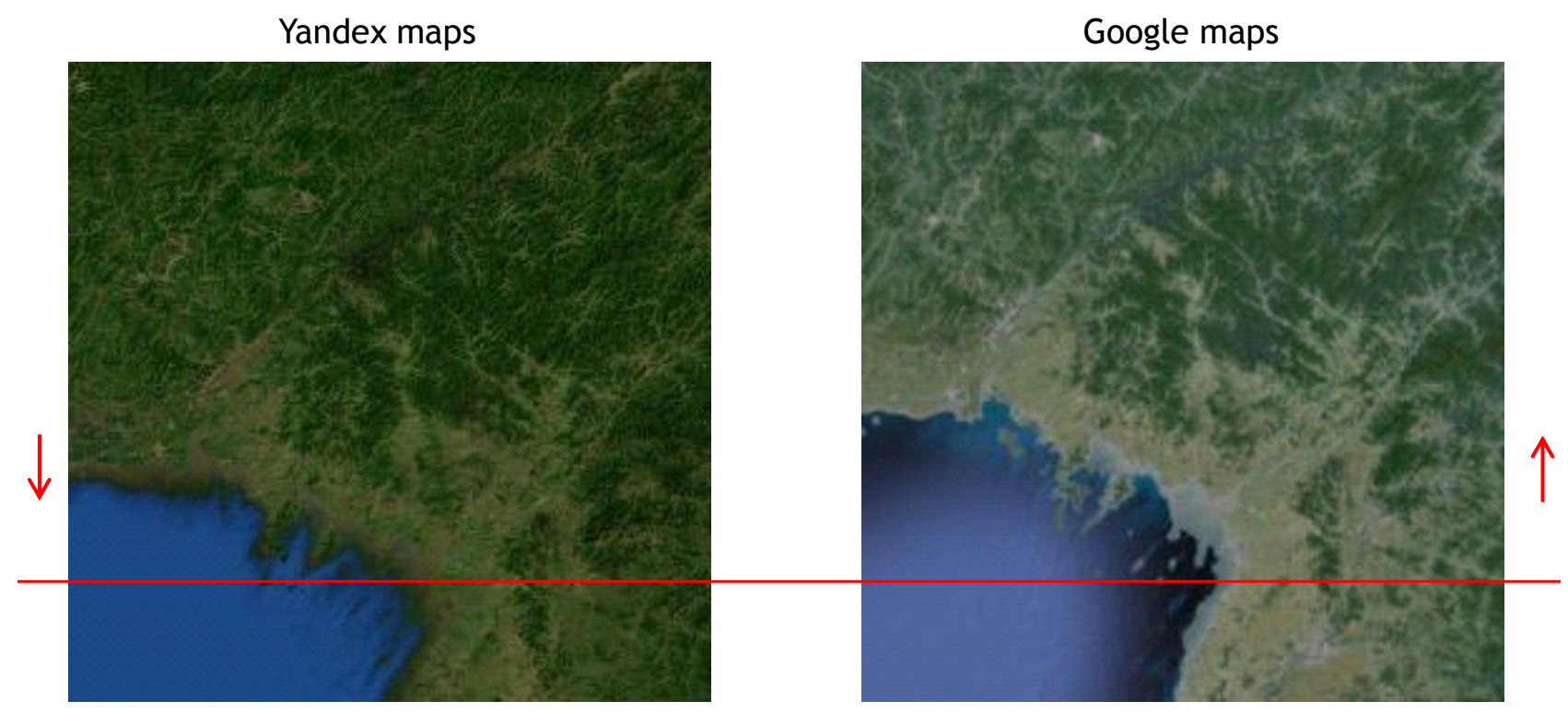

Fig. 7. Difference between the Google and Yandex map tiles of the selected region.

sources is the DIVA-GIS [14]. We have stored vector/ contour maps of more than 200 countries with provinces, rivers, and cities, Fig. 4.

Owing to this work, one can navigate through the list of countries with already prepared maps in CGIS, like a world interactive atlas [15]. This database allows us to effectively create maps of any regions for research.

Any area/region on the world map can be marked with a rectangle in the CGIS interface and stored in a temporary folder in our database for further work. Then the combined raster and vector layers are created for the map of this region. Then we can overlay the layers of texts, energy data, and geospatial objects on this map.

We have developed algorithms for searching objects or groups of objects united by one attribute inside a closed polygon (Fig. 5), for example, if we need to find some objects belonging to a specific country or province (an object inside a closed polygon). The selection of a rectangular area on a world map significantly reduces the number of closed polygons.

\section{TECHNICAL FEATURES AND PROBLEMS}

CGIS allows constructing hybrid maps that contain vector and raster layers of the map, with the energy infrastructure overlaid on it.

The CGIS database contains:

- Raster data, including space satellite snapshots (tiles) of the selected territory (geospatial data on countries and regions used as the background);

- Vector data, including the data in the SHP format, that contain geo-coordinates of power plants, country borders, and administrative divisions;

- Energy infrastructure data, including technical and economic data on power plants, electric ties, energy power systems (EPS), and others.
With 0 zoom level on Google and Yandex maps, the entire Earth is placed in one square tile (a side equals the equator length). For the other levels, the number of tiles is determined by $\mathrm{N}=\mathrm{H}$ (height) $\cdot \mathrm{W}$ (width), Fig. 6 .

Due to a change in the policy for providing free Google maps, it was necessary to convert all maps to Yandex maps. The technologies of map constructing are based on the tiles downloaded from the Internet and "glued," i.e., selected territory snapshots made by space satellites with the pictures differing (offsetting) in their physical coordinates, Fig. 7.

The problem is that Google uses the Mercator spherical projection (EPSG: 3857 - WGS 84/Pseudo-Mercator), and Yandex employs the Mercator elliptical projection (EPSG: 3395 - WGS 84/World Mercator) [16].

We implemented algorithms for converting coordinates from one system to the other so that the vector layers exactly "fit" into the specified area. Additionally, the algorithms were implemented to interactively determine the geographical coordinates of any object on the map. Algorithms were designed to search for the database objects in any region.

\section{CONCLUSION}

The maps of about 200 countries with administrative divisions were constructed and stored in the CGIS database. Search geocoding algorithms were implemented for energy objects in any region of the world. Statistical data processing algorithms were developed (output of the total number of energy objects in a given territory, and others). Algorithms were designed for conversion from Google map to Yandex map to enable vector layers to exactly "fit" into the specified area.

The atlases built by CGIS are used at MESI to plot solutions obtained with the optimization model ORIRES 
(which reflects the optimal operation of the interconnected power systems in different scenarios) on a map of the selected territory or region.

\section{ACKNOWLEDGMENT}

The research was carried out under State Assignment Project (no. FWEU-2021-0001) of the Fundamental Research Program of the Russian Federation 2021-2025.

\section{REFERENCES}

[1] Belyaev, L. Chudinova, O. Khamisov, G. Kovalev, L. Lebedeva, S. Podkovalnikov, and V. Savel'ev, "Studies of interstate electric ties in Northeast Asia," International Journal of Global Energy Issues, vol. 17, no. 3, pp. 228-249, 2002.

[2] Podkovalnikov, V. Savelev, O. Khamisov, L. Chudinova, "Justification of Effectiveness of International PowerInterconnections with Separation of Effects between Participants," Automation and remote control, vol. 10, pp. 1756-1765, 2018. DOI: $10.1134 / \mathrm{S} 0005117918100028$

[3] Podkovalnikov, I. Trofimov, L. Trofimov, L. Chudinova, L. Belyaev, V. Savelev, "Computing and Information System for Research of Prospective Electric Power Grids Expansion," Yugoslav Journal of Operations Research, [S.1.], vol. 29, no. 4, pp. 465-481, 2019. DOI: 10.2298/YJOR1811.

[4] Podkovalnikov, I. Trofimov, and L. Trofimov, "Data processing and optimization system to study prospective interstate power interconnections," in 10th International Conference on Asian Energy Cooperation (AEC 2017), E3S Web Conf., vol. 27, pp. 32-40, DOI: 10.1051/e3sconf/20182701007.

[5] Energy Statistical Analytical Service. Available at: http://www.esas.com.ru/en, [accessed 26 July 2019].

[6] Podkovalnikov, I. Trofimov, L. Trofimov, and L. Chudinova, "The Computing and Information System for Study of Scenarios for Interstate Power Grid Expansion," in IEEE 2019 16th International Conference on Electrical Engineering/Electronics, Computer, Telecommunications and Information Technology (ECTI-CON), Pattaya, Chonburi, Thailand, 2019, pp. 1-4. DOI: 10.1109/ECTICON47248.2019.8955179

[7] Omatsu, "Interim Report by Asia International Grid Connection Study Group," in 10th International Conference on Asian Energy Cooperation (AEC 2017), E3S Web Conf., vol. 27, pp. 9-18, 2018.

[8] Xuming, "Application and research of global grid database design based on geographic information," Academic Journal of the Global Energy Interconnection Development and Cooperation Organization, vol. 1, no. 1, pp. 87-95, 2018.

[9] The United Nations Economic and Social Commission for Asia and the Pacific (UN ESCAP). Available at: https://unescap.org/research [accessed: 25 March 2019].
[10] Asia Pacific Energy Portal, UN ESCAP. Available at: https://asiapacificenergy.org/, [accessed: 23 April 2019].

[11] Global Energy Interconnection Development and Cooperation Organization (GEIDCO). Available at: https://en.geidco.org/journal/ [accessed: 07 August 2019].

[12] ArcGIS. Mapping and Analyzing. Available at: https://www.arcgis.com/, [accessed: 22 January 2020].

[13] MapInfo. GIS Mapping. Available at: http://www. mapinfo.ru/, [accessed: 23 January 2020].

[14] DIVA-GIS. Available at: https://www.diva-gis.org/, [accessed: 13 April 2019].

[15] O. Zolotova, E. Skupinova, D. Bondarenko, V. Drobyshev, "GIS and Atlas mapping," ArcReview Electronic Journal, vol. 1, no. 44, 2008. (In Russian).

[16] World Geodetic System Projections. Available at:_https://gisgeography.com/ellipsoid-oblatespheroid-earth/, [accessed: 10 February 2020].

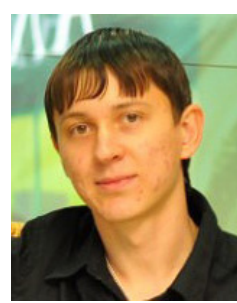

Ivan Trofimov is a junior researcher at the Melentiev Energy Systems Institute of the Siberian Branch of the Russian Academy of Sciences. His research interests are web \& information technologies and their implementation in the energy field.

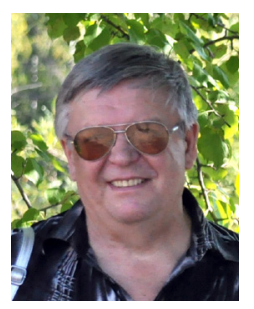

Leonid Trofimov is a lead programmer at the Melentiev Energy Systems Institute of the Siberian Branch of the Russian Academy of Sciences. His professional interests are software development, data visualization, geoinformation systems, object data structure, and data processing. 